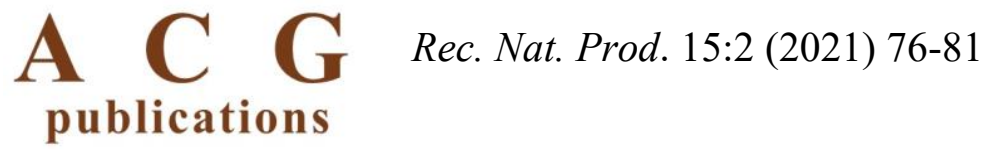

records of natural products

\title{
A New Alkaloid Glycoside from the Stems of Zanthoxylum dissitum Hemsl.
}

\author{
Xian Wei $\oplus^{1_{+}}$, Yang Tan $\oplus^{2+}$, Yuhe Shi $\oplus^{2}$, Yuan yuan $\oplus^{2,3^{*}}$ and \\ Shunmin Li ${ }^{2^{*}}$

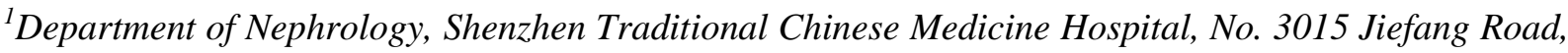 \\ Shenzhen, Guangdong, 518034, P. R. China \\ ${ }^{2}$ Pharmacy of College, Hunan University of Chinese Medicine, No. 300 Xueshi Road, Changsha, \\ Hunan, 410208, P. R. China \\ ${ }^{3}$ Hunan Provincial Engineering Technology Center of Standardization and Function of Chinese \\ Herbal Medicine, No. 300 Xueshi Road, Changsha, Hunan, 410208, P. R. China
}

(Received May 07, 2020; Revised July 07, 2020; Accepted July 13, 2020)

\begin{abstract}
A new alkaloid glycoside (1) and six known alkaloids (2-7) were isolated from the stems of Zanthoxylum dissitum Hemsl. The structure of compound $\mathbf{1}$ was elucidated by UV, IR, ${ }^{1} \mathrm{H}$ NMR, ${ }^{13} \mathrm{C}$ NMR and mass spectroscopic analyses. All compounds obtained in this research were evaluated for their inhibitions against NO release from LPS-activated RAW264.7 macrophages. Compounds 1-3, 6 and 7 showed significant inhibition activities with $\mathrm{IC}_{50}$ values of $26.12 \pm 0.81,8.41 \pm 0.23,13.75 \pm 0.54,6.97 \pm 0.77$, and $5.78 \pm 0.42 \mu \mathrm{M}$, respectively.
\end{abstract}

Keywords: Zanthoxylum dissitum Hemsl.; alkaloid; macrophages; NO. (C) 2020 ACG Publications. All rights reserved.

\section{Introduction}

The genus Zanthoxylum belongs to the Rutaceae family, including more than 250 species worldwide, ranges from the subtropical to the tropic zones. Among all suchspecies, 45 are distributed in China. Some fruits of these species are well known spices, while some species are widely used as folk medicine [1,2]. In addition, part of plants belong to Zanthoxylum are economically important for food, timber industries and wood working [3,4].

Zanthoxy lumdissitum Hemsl. (Z. dissitum), a climbing or sprawling shrub woody vine in the forest and mountains, is a member of Zanthoxylum plants, which are found in the southwest of Shanxi, Guangxi and Hunan provinces [5]. The roots, stems and leaves of $Z$. dissitum have been used as Chinese folk medicine for women's disorders, pains in the loin, limbs and arthritis. Previous phytochemical studies have repoted that the stem extracts from $Z$. dissitum exhibit powerful antimicrobial and anti-tumor activities [6,7]. Some interesting secondary metabolites such as alkaloids with anti-inflammatory, anti-microbial, and anti-tumor activities have also beenfound in this genus $[8,9]$. To search for structurally unique and biologically natural components [10], we have isolated and

\footnotetext{
$\dagger$ These authors contributed to this work equally.

* Corresponding authors: E-Mail: zyylishunmin@yeah.net (Shunmin Li) and 49464565@qq.com (Yuan Yuan). The article was published by ACG Publications http://www.acgpubs.org/journal/records-of-natural-products March-April 2021 EISSN:1307-6167 DOI: http://doi.org/10.25135/rnp.191.20.05.1643
} 
identified compounds from the stems of $Z$. dissitum. During this process, a new alkaloid glycoside (1), along with six known alkaloids (2-7), were obtained (Figure 1). Herein, the process of isolation, structural determination, and biological detection of these compounds are described.

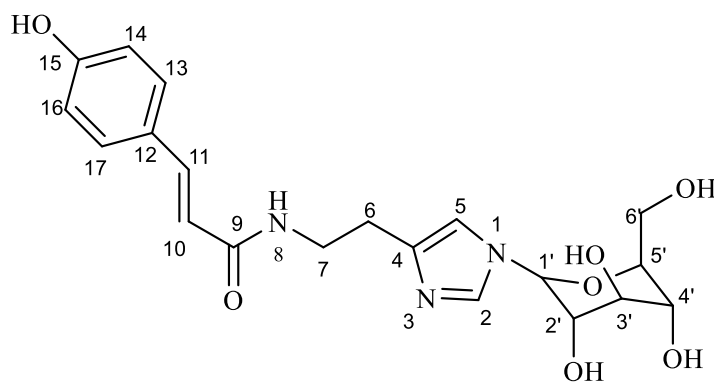<smiles>COc1c2ccccc2nc2occc12</smiles><smiles>COc1ccc2c(cnc3c4cc5c(cc4ccc23)OCO5)c1OC</smiles>

5<smiles>COc1c2ccoc2nc2c(OC)cccc12</smiles>

3<smiles></smiles><smiles>Cn1c(=O)ccc2ccccc21</smiles>

4<smiles></smiles>

7

Figure 1. The structures of compounds 1-7

\section{Materials and Methods}

\subsection{General}

A Bruker Avance III-600 spectrometer was used for NMR detections (Bruker, Shanghai, China). An Agilent Cary 3500 UV-visible spectrometer (Agilant, Santa Clara, CA, USA) and Bruker VERTEX 80/80v Fourier transform infrared spectrometer were used to detect UV and IR spectra of compound 1, respectively. A Bruker Impact II mass spectrometer was used to obtain ESI-MS spectra. The MCI gel was purchased from Mitsubishi Chemical Holdings (Tokyo, Japan). Macroporous adsorption resin was purchased from Dalian Meilun Biotechnology (Dalian, China). Both column chromatography (CC) silica gel and thin layer chromatography (TLC) silica gel were purchased from Qingdao Haiyang Chemical (Qingdao, China). Sephadex LH-20 was purchased from Pharmacia (Rockville, MD, USA). All organic solvents used in this research were purchased from Tianjin Henxing Chemical Reagent (Tianjin, China).

Mouse mononuclear RAW264.7 macrophages were kindly provided by the Stem Cell Bank, Chinese Academy of Sciences (Shanghai, China). Consumables for cell experiments were purchased from NEST Biotech (Wuxi, China). Both high-glucose Dulbecco's-Modified eagle medium (DMEM) 
and fetal calf serum were purchased from Gibco by Thermo Fisher Scientific (Waltham, MA, USA). Lipopolysaccharide (LPS) was purchased from Sigma-Aldrich (St. Louis, MO, USA). NO detection kit was purchased from Beyotime Biotechnology (Shanghai, China).

\subsection{Plant Material}

The stems of Zanthoxylum dissitum were collected in September 2018 from Zhangjiajie, Hunan Province, China, and authenticated by Professor Bingmei Xiao, School of Pharmacy, Hunan University of Chinese Medicine. A voucher specimen (No. DMZ201809) was deposited with Hunan Provincial Engineering Technology Center of Standardization and Function of Chinese Herbal Medicine.

\subsection{Extraction and Isolation}

The air-dried stems of $Z$. dissitum Hemsl. (10 kg) were cut into small pieces and extracted three times with $70 \%$ ethanol by refluxing for 2 hours each time. After evaporation under reduced pressure, a dark-brown fluid extract $(1.2 \mathrm{~kg})$ was obtained. The extracts were suspended in $\mathrm{H}_{2} \mathrm{O}$ and then successively extracted with $\mathrm{CHCl}_{3}$, EtOAc, and n-BuOH.

The $\mathrm{CHCl}_{3}$ portion $(40.3 \mathrm{~g})$ was subjected to silica $\mathrm{CC}$ and eluted with a gradient system from $\mathrm{C}_{6} \mathrm{H}_{12} / \mathrm{CHCl}_{3}(10: 1-0: 1, \mathrm{~V}: \mathrm{V})$ to $100 \% \mathrm{MeOH}$ with $10 \%$ increments. Based on the TLC detection, similar fractions were combined to obtain 11 fractions $(\mathrm{C} 1-11)$. Fraction $\mathrm{C} 8(3.8 \mathrm{~g})$ was applied to silica CC using a $\left[\mathrm{C}_{6} \mathrm{H}_{12} / \mathrm{CHCl}_{3}(8: 1)\right.$ to $\mathrm{CHCl}_{3} / \mathrm{MeOH}(1: 1)$, v: v] wash to obtain six fractions (C8-1C8-6). Fraction 8-4 (2.1 g) was loaded on a MCI gel and eluted with $\mathrm{H}_{2} \mathrm{O}$ and 30\%, 50\%, 70\%, 90\% and $100 \%$ EtOH to obtain four parts (C8-4-1 to C8-4-4) and compound 2 (8.4 mg). Fraction C8-4-2 $(1.1 \mathrm{~g})$ was further repeatedly purified by Sephadex $\mathrm{LH}-20 \mathrm{CC}\left[\mathrm{CHCl}_{3} / \mathrm{MeOH}\right.$ (1:1), v:v] and preparative TLC $\left[\mathrm{CHCl}_{3} / \mathrm{MeOH}(5: 1)\right.$, v: v] to obtain compounds $3(8.5 \mathrm{mg})$ and $4(9.6 \mathrm{mg})$. Fraction C10 (8.1 g) was also successively separated and purified by a MCI gel $\left[\mathrm{MeOH} / \mathrm{H}_{2} \mathrm{O}(0: 100-100: 0)\right.$, v:v], then further purified by $\mathrm{CC}\left(\mathrm{C}_{6} \mathrm{H}_{12} / \mathrm{CHCl}_{3} 5: 1, \mathrm{~V}: \mathrm{V}\right)$ with $5 \%$ increment and Sephadex LH-20 $\left[\mathrm{CHCl}_{3} / \mathrm{MeOH}(1: 1), \mathrm{v}: \mathrm{v}\right]$, to obtain compound 5 (10.4 mg).

The $n$-BuOH portion (65.2 g) was suspended with $\mathrm{H}_{2} \mathrm{O}$ to obtain two parts. The water soluble part was subjected to macroporous adsorption resin (AB-8) with a step-gradient of $\mathrm{H}_{2} \mathrm{Oand} 30 \%, 50 \%$, $70 \%, 90 \%$ and $100 \% \mathrm{MeOH}$ to yield four subfractions (B-1 to B-6). B-2 (35.3 g) was further purified by a silica gel column, using the gradient systems of $\mathrm{CHCl}_{3} / \mathrm{EtoAc}(2: 1$, v:v) to $100 \% \mathrm{MeOH}$ with a final $\mathrm{MeOH} / \mathrm{H}_{2} \mathrm{O}(75: 15, \mathrm{v}: \mathrm{v})$ wash to obtain compound $\mathbf{1}(36.8 \mathrm{mg})$. Compounds $6(33.7 \mathrm{mg})$ and 7 $(22.0 \mathrm{mg})$ were obtained from B-4 $(6.2 \mathrm{~g})$ and B-5 (10.0 g), respectively.

\subsection{Spectroscopic Data}

Colorless needle crystal; UV ( $\left.\mathrm{H}_{2} \mathrm{O}\right) \lambda \max$ : 223, $298 \mathrm{~nm}$; IR (KBr) max 3300, 2964, 1692, 1603, 1513, 1445, 832.14, $982.96 \mathrm{~cm}^{-1}$; $1 \mathrm{H} \mathrm{NMR}\left(\mathrm{CDCl}_{3}, 600 \mathrm{MHz}\right)$, see Table $1 ;{ }^{13} \mathrm{C}$ NMR $\left(\mathrm{CDCl}_{3}, 150\right.$ $\mathrm{MHz}$ ), see Table 1; HR-ESI-TOF-MS (positive ion model) $\mathrm{m} / \mathrm{z} 420.1774[\mathrm{M}+\mathrm{H}]^{+}$, (calculated for $\mathrm{C}_{20} \mathrm{H}_{26} \mathrm{~N}_{3} \mathrm{O}_{7}, m / z$ 419.1693).

\subsection{Determination of Inhibition NO Release}

RAW264.7 cells were cultured in DMEM with $10 \%$ fetal calf serum in a humidified atmosphere of $5 \% \mathrm{CO}_{2}$ at $37{ }^{\circ} \mathrm{C}$. Cells under logarithmic phase were suspended, and then plated in 96-well plates at $1 \times 10^{5}$ cells/well. The old culture medium was removed after the cells were incubated for $24 \mathrm{~h}$ at $37^{\circ} \mathrm{C}$. A total of $200 \mathrm{ng} / \mathrm{mL}$ LPS, combined with various concentrations of test samples, was added for intervening RAW264.7 cells. At $24 \mathrm{~h}$ after drug intervention, the cell culture medium in each well was collectedcentrifuged at $300 \times \mathrm{g}$ for $10 \mathrm{~min}$, and the liquid supernatant was use to test the concentrations of NO using an assay kit. Dexamethasone was used as a positive control. Each experiment was run in triplicate and averaged [11]. 


\section{Results and Discussion}

\subsection{Structure Elucidation}

Compound 1 had a colorless needle crystal form. The molecular composition was determined as $\mathrm{C}_{20} \mathrm{H}_{25} \mathrm{~N}_{3} \mathrm{O}_{7}$, from the ESI-MS with a molecular ion peak found $\mathrm{m} / z 420.1774[\mathrm{M}+\mathrm{H}]^{+}$, (calculated for $\mathrm{C}_{20} \mathrm{H}_{26} \mathrm{~N}_{3} \mathrm{O}_{7}, m / z$ 419.1693). This molecule had 10 degrees of unsaturation. The UV spectrum showed the existences of a conjugated system $(223 \mathrm{~nm})$ and a carbonyl group $(298 \mathrm{~nm})$. The IR spectrum showed a functional hydroxyl group $1\left(3300 \mathrm{~cm}^{-1}\right)$, para-substituted and conjugated benzene ring (2964, 1603, 1513, 1445, and $\left.832 \mathrm{~cm}^{-1}\right)$, carbonyl $\left(1692 \mathrm{~cm}^{-1}\right)$, and trans-double bond $\left(982 \mathrm{~cm}^{-1}\right) . \mathrm{In}$ the ${ }^{13} \mathrm{C}$ NMR spectrum, it had resonated 20 carbons, which were classified as three methylenes, thirteen methines, and four quarternary carbons. A phenolic proton signal of $\delta: 9.82(1 \mathrm{H}, \mathrm{s}, \mathrm{H}-1)$ was observed in the ${ }^{1} \mathrm{H}$ NMR spectrum. By reviewing the literature, this data was proved to be consistent with the hydroxyl signal in compounds containing 4-hydroxycinnamic acid amide [12]. There is a set of adjacently coupled proton signals of $\delta: 7.37(2 \mathrm{H}, \mathrm{d}, J=8.6 \mathrm{~Hz})$ and $6.77 \mathrm{in}$ the aromatic region $(2 \mathrm{H}$, $\mathrm{d}, J=8.5 \mathrm{~Hz}$ ), combined with two strong carbon signals in the ${ }^{13} \mathrm{C}$ NMR spectrum $(\delta: 129.2$ and 115.7), which indicated that the compound had para-disubstituted benzene ring. Peaks at $\delta: 7.31(1 \mathrm{H}, \mathrm{d}$, $J=15.7)$ and $\delta: 6.39(1 \mathrm{H}, \mathrm{d}, J=15.7 \mathrm{~Hz})$ were related in the ${ }^{1} \mathrm{H}-{ }^{1} \mathrm{H}$ COSY spectrum, which showed a trans-double bond exist in this compound. The connection between the benzene ring and the double bond was determined by the correlation of $\mathrm{CH}-13,17\left(\delta_{\mathrm{H}}: 7.37\right)$ to $\mathrm{C}-11\left(\delta_{\mathrm{C}}: 138.6\right)$ in the HMBC spectrum (Figure 2). In addition, the HMBC spectrum also showed the proton CH-11 $\left(\delta_{\mathrm{H}}: 7.30\right)$ connected with the double bond coupled with carbonyl C-9 $\left(\delta_{\mathrm{C}}: 163.5\right)$. The hydrogen atom $\mathrm{NH}-8\left(\delta_{\mathrm{H}}\right.$ : 8.04) was correlated with $\mathrm{C}-9\left(\delta_{\mathrm{C}}: 163.5\right)$ and C-7 $\left(\delta_{\mathrm{C}}: 38.8\right)$. The correlation of $\mathrm{CH}_{2}-6\left(\delta_{\mathrm{H}}: 2.61\right)$ to $\mathrm{CH}_{2}-7\left(\delta_{\mathrm{H}}: 3.38\right)$ was observed in the ${ }^{1} \mathrm{H}-{ }^{1} \mathrm{H}$ COSY spectrum. In the HMBC spectrum, $\mathrm{CH}_{2}-6\left(\delta_{\mathrm{H}}\right.$ : $2.61)$ to $\mathrm{C}-7$ ( $\left.\delta_{\mathrm{C}}: 38.8\right), \mathrm{C}-4\left(\delta_{\mathrm{C}}: 138.6\right)$ and C-5 (114.2) in the imidazole ring showed the connection of $\mathrm{CH}_{2} \mathrm{CH}_{2}$ and the imidazole ring. The NMR spectrum of the compound had a similar structure a aglycone. disolved in $\mathrm{CDCl}_{3}$, the chemical shifts of $\mathrm{C}-2,4$ and 5, which maked up the imidazole ring combine with two nitrogen atoms, were 136.1, 136.1, and 117.9, respectively [13]. Combined with the data of the HMBC spectrum, we speculated that the imidazole ring exists in the structure of compound 1. In the ${ }^{13} \mathrm{C}$ NMR spectrum, $\delta_{\mathrm{C}}: 85.3,72.5,77.2,69.3,79.6$, and 60.9 belonged to glycosyl signals. The correlation of $\mathrm{CH}-1$ ' $\left(\delta_{\mathrm{H}}: 5.03\right)$ to $\mathrm{C}-4\left(\delta_{\mathrm{C}}: 138.9\right)$ and $\mathrm{C}-5\left(\delta_{\mathrm{C}}: 114.2\right)$ indicated the part where the glycosyl connected with the aglycone in the imidazole ring. The signal of the anomeric carbon in the glycosyl was $\delta_{\mathrm{C}}$ : 85.3 , which implied that the glycosyl was connected with the nitrogen atom in the heterocyclic ring. In the spectral data of the compound with similar structure, the chemical shift of carbon at the same position was 87.2, which also supported our speculation [14] (See supporting infromationTable S1). The chemical shifts of the carbon and protons of the glycosyl in compound 1 were close to the relevant data of casimiroedine [13]. The coupling constant of the proton connecting with the anomeric carbon inthe glycosyl was $9.06 \mathrm{~Hz}$, indicating that the glycosyl belonged to a $\beta$ configuration. The structure of compound $\mathbf{1}$ was determined and named as dissitumine.

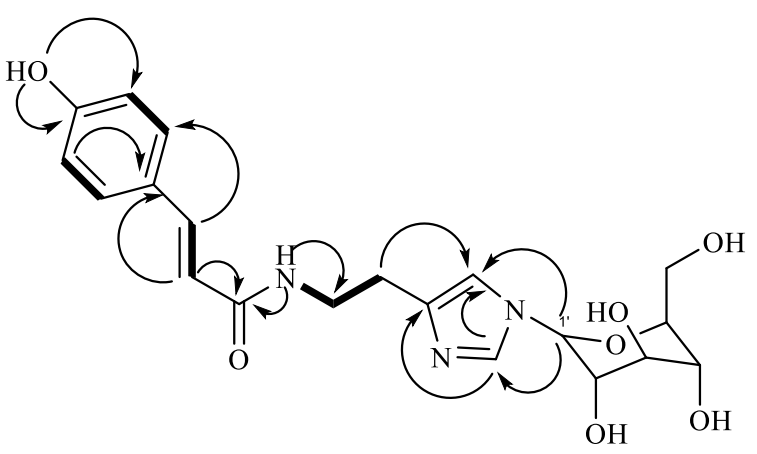

Figure 2. Key $\mathrm{HMBC}$ and ${ }^{1} \mathrm{H}^{1}{ }^{1} \mathrm{H}$ COSY correlations of compound 1 ( $\left.\mathrm{OHMBC}, \longrightarrow{ }^{1} \mathrm{H}^{-1} \mathrm{H} \mathrm{COSY}\right)$. 
By querying the SciFinder database, we found there are two compounds with a similar structure to compound 1. The chemical shifts of their benzene ring and the double bond connected to the benzene ring were different from that of dissitumine, and there was an additional signal of a methyl group connected to the nitrogen atom in those known compounds. Thus, we speculate that compound $\mathbf{1}$ was a new alkaloid glycoside. Additionally, known compounds were identified as dictamnine (2), $\gamma$ fagarine (3), 4-methoxy-1 methyl-2-quinolone (4), norchelerythrine (5), sanguinarine (6), and nitidine (7). The structures of the above mentioned compounds are shown in Figure 1.

\subsection{The Assay of NO Release Inhibition}

All compounds (1-7) were assessed for their activities of inhibiting NO release from LPSstimulated RAW264.7 mouse macrophage cells [11]. Compounds $\mathbf{4}$ and $\mathbf{5}$ did not show significant results at high concentrations $(50 \mu \mathrm{M})$. Compounds $\mathbf{1}-\mathbf{3}, \mathbf{6}$, and $\mathbf{7}$ were evaluated for their activities to the inhibit macrophage release of inflammatory cytokines, and showed $\mathrm{IC}_{50}$ values of $26.12 \pm 0.81$, $8.41 \pm 0.23,13.75 \pm 0.54,6.97 \pm 0.77$, and $5.78 \pm 0.42 \mu \mathrm{M}$, respectively. Among those isolated compounds, dictamnine (2), sanguinarine (6), and nitidine(7) showed strong activity with $\mathrm{IC}_{50}$ values lower than $10.00 \mu \mathrm{M}$. Moreover, the activity of $\gamma$-fagarine (3) is weaker than dictamnine (2), which may imply that adding a methoxy group to the benzene ring of a uinolone alkaloid will down-regulate its activity to inhibit NO release from LPS-stimulated macrophages.

Table 1. ${ }^{1} \mathrm{H}(600 \mathrm{MHz})$ and ${ }^{13} \mathrm{C}$ NMR $(150 \mathrm{MHz})$ data of compound $1(\delta$ in ppm, $J$ in $\mathrm{Hz})$ in DMSO-d 6

\begin{tabular}{|c|c|c|c|c|}
\hline Position & $\boldsymbol{\delta}_{\mathbf{H}}$ & $\boldsymbol{\delta}_{\mathbf{C}}$ & HMBC & COSY \\
\hline 2 & $7.60(1 \mathrm{H}, \mathrm{s})$ & 136.5 & $\mathrm{C}-2$ and 5 & - \\
\hline 4 & - & 138.6 & - & - \\
\hline 5 & $7.03(1 \mathrm{H}, \mathrm{s})$ & 114.2 & C-2 and 4 & - \\
\hline 6 & $2.61(2 \mathrm{H}, \mathrm{t}, 7.6)$ & 28.4 & C-4, 5 and 7 & - \\
\hline 7 & $3.38(2 \mathrm{H}, \mathrm{m})$ & 38.8 & C-4, 6 and 9 & H-6 and 8 \\
\hline 8 & $8.04(1 \mathrm{H}, \mathrm{t}, 5.6)$ & - & C-7 and 9 & $\mathrm{H}-7$ \\
\hline 9 & - & 163.5 & - & - \\
\hline 10 & $6.39(1 \mathrm{H}, \mathrm{d}, 15.7)$ & 118.8 & C-9 and 12 & $\mathrm{H}-11$ \\
\hline 11 & $7.30(1 \mathrm{H}, \mathrm{d}, 15.7)$ & 138.9 & C-9,10, 13 and 17 & $\mathrm{H}-10$ \\
\hline 12 & - & 125.9 & $163.5,118.8,129.2$ & - \\
\hline 13,17 & $7.37(2 \mathrm{H}, \mathrm{d}, 8.6)$ & 129.2 & C- $11,13,14,16$ and 17 & $\mathrm{H}-14$ and 16 \\
\hline 14,16 & $6.78(2 \mathrm{H}, \mathrm{d}, 8.5)$ & 115.7 & $\mathrm{C}-12,14,15$ and 16 & $\mathrm{H}-13$ and 17 \\
\hline 15 & - & 158.8 & & - \\
\hline $1^{\prime}$ & $5.03(1 \mathrm{H}, \mathrm{d}, 9.1)$ & 85.3 & $\mathrm{C}-2,5,2^{\prime}, 3^{\prime}$ and $5^{\prime}$ & H-2' \\
\hline $2^{\prime}$ & $3.46(1 \mathrm{H}, \mathrm{m})$ & 72.5 & C- 3 ' and $1^{\prime}$ & $\mathrm{H}-1^{\prime}$ and $\mathrm{OH}-2^{\prime}$ \\
\hline $3^{\prime}$ & $3.28(1 \mathrm{H}, \mathrm{m})$ & 77.2 & $\mathrm{C}-3^{\prime}$ & OH-3' \\
\hline $4^{\prime}$ & $3.16(1 \mathrm{H}, \mathrm{m})$ & 69.3 & $\mathrm{C}-2^{\prime}$ & OH-4' \\
\hline $5^{\prime}$ & $3.32(1 \mathrm{H}, \mathrm{m})$ & 79.6 & C-4' and 6' & - \\
\hline $6^{\prime}$ & $3.68,3.42($ each $1 \mathrm{H}, \mathrm{m})$ & 60.9 & C-4' and $5^{\prime}$ & H-6' and $\mathrm{OH}-6^{\prime}$ \\
\hline
\end{tabular}

\section{Acknowledgments}

This work was partially supported by Hunan University of Chinese Medicine First-class Disciple Construction Project of Chinese Material Medica (China). 


\section{Supporting Information}

Supporting Information accompanies this paper on http://www.acgpubs.org/journal/recordsof-natural-products

\section{ORCID}

Xian Wei: 0000-0003-0539-2675

Yang Tan: $\underline{0000-0002-4834-6292}$

Yuhe Shi: 0000-0001-8456-2585

Yuan Yuan: 0000-0001-7543-5808

Shunmin Li: $0000-0001-5524-4238$

\section{References}

[1] S. K. Adesina (2005). The Nigerian Zanthoxylum: chemical and biological values, Afr. J. Trad. Complement. Alterna. Med. 2, 282-301.

[2] M. Anza, E. Haile, S. Tadesse, F. Mammo and M. Endale (2014). A coniferyl alcohol derivative from the roots of Zanthoxylum chalybeum, J. Coast. Life Med. 2, 970-974.

[3] F.Alam, Q. N. Saqib and M. Ashraf (2018). Zanthoxylum armatum DC extracts from fruit, bark and leaf induce hypolipidemic and hypoglycemic effects in mice- in vivo and in vitro study, BMC Complement. Alternat. Med. 18, 68. oi:10.1186/s12906-018-2138-4.

[4] X. Yang (2008). Aroma constituents and alkylamides of red and green huajiao (Zanthoxylum bungeanum and Zanthoxylum schinifolium), J. Agric. Food Chem. 56, 1689-1696.

[5] State Administration of Traditional Chinese Medicine, Chinese Materia Medica Editorial Board (1999). Chinse Materica Medica. Shanghai Scientific and Technical Publishers.

[6] S. P. Xiao, J. H. Zhan, Y. L. Zhang, Y. Tan, Y. C. Meng and G.. Pei (2016). Antibacterial and inhibitory effects of different extracts from stem of Zanthoxylum dissitum Hemsl on MCF-7 Cell, Nat. Prod. Res. Dev. 28,1460-1463, 1469.

[7] Y. Yuan, C. Xiao, X. H. Liao, Y. Z. Ding and G. Pei (2011). Inhibitory action of nitidine and zanthobungeanine on lung adenocarcin adenocarcinoma A549 cell, Anti-tumor Pharm. 1, 30-32.

[8] C. Xiao, Y. Yuan, Y. Z. Ding, T. F. Jin and G. Pei (2011). Study on the alkaloids from the stem of Zanthoxylum dissitum, J. Chin. Med. Mater. 34,551-553.

[9] S, Liu, W. Zhang, G. X. He, P. Lei, X. Z. Li and Y. Z. Liang (2009). Study on chemical constituents from the stem of Zanthoxylum dissitum, China J. Chin. Mate. Med. 34, 571-573.

[10] D. B. Zhang, J. G. Yu, Z. Zhang, Y. N. Liang, Z. S. Tang and Z. Wang (2020). Structure, absoluteconfiguration and biological evaluation of a new labdane diterpenoid from Jatropha podagrica, Rec. Nat. Prod. 14, 335-360.

[11] L. Li, W. Du and W. Wang (2019). Evaluation of the antioxidative and anti-inflammatory effects of the extract of Ribes mandshuricum (Maxim.) Kom. leaves, Rec. Nat. Prod. (2019) 13; 141 - 155

[12] P. Beisenhan, T. Zhang, B. Makabel and Z. M. Zou (2018). Chemical constituents of Pothos chinensis, J. Int. Pharm. Res. 45, 61-65.

[13] R. L. Arslanian, B. Mondragon, F. R. Stermitz and K. L. Marr (1990). Acyl histamines and a rare protopine-type alkaloid from leaves of Zanthoxylum dipetalum, Biochem. System. Ecol. 18, 345-347.

[14] W. F. Reynolds, R. G. Enriquez, G. A. Magos and D. Gnecco (2000). Total assignment of the ${ }^{1} \mathrm{H}$ and ${ }^{13} \mathrm{C}$ NMR spectra of casimiroedine and its peracetylated derivative, Magn. Reson. Chem. 38, 366-369.

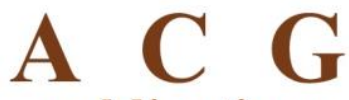

publications

(C) 2020 ACG Publications 